\title{
A review on Aerial refueling hose used in fighter aircraft
}

\author{
${ }^{1}$ Mr. Tejas.S.Sali, ${ }^{2}$ Pro. Arif. K. Mansuri, ${ }^{4}$ Prof. Ajit S. Thorat \\ ${ }^{1}$ Mechanical Design Department, ${ }^{2}$ Dean Administration, Sandip University, Nasik, Maharashtra, \\ India. 1 tejassali193@gmail.com, ${ }^{2}$ arif.mansuri@ sandipuniversity.com, \\ 4ajit.thorat@sandipuniversity.com
}

${ }^{3}$ Dr. Ajit Bhandakkar, Chief Manager, Design Indigenisation AURDC, HAL, Nasik, India.

Abstract: It is a review paper on refueling hose which is used in aircrafts. In fighter aircraft refueling is done in air, with the help of hose $\&$ refueling pod or refueling tanker aircrafts. Hose is connected to the pod and pod is mounted on adapter beam which is attached to the air craft. One end of hose is called drogue which is use to connect the probe or another aircraft beam to fuelling the aircraft. The probe $\&$ drogue contact is modelled with a unidirectional magnet like attractor, which lets the drogue being catched by the probe tip when coming close enough. Pod which contains hose is designed for installation onboard deck launched aircraft. The hose design is decided from some standards, its materials must suit for required application and it have to sustain various conditions in which its working which is discuss in this paper.

Keywords - Refueling Hose, Probe, Drogue, Refueling pod, Aerial Refueling, Tanker, Receiver

\section{INTRODUCTION}

A fighter aircraft is also known as military aircraft is designed in such way that for air-to-air and air-to ground combat operation against enemy aircraft. In fighter aircraft refueling is done in air only by hose with the help of refueling pod or refueling tanker aircrafts. Hose is connected to the pod and pod is mounted on adapter beam which is attached to the air craft. One end of hose is drogue which is use to connect the probe or another aircraft beam to fuelling the aircraft. Probe \& drogue contact is modelled with an unidirectional magnet like attractor, which lets the drogue being catched by the probe tip when coming close enough. Refueling pod is designed for installation on board the deck-launched aircraft. Arrangement of the pod onboard the craft provides the warship air unit with a self-contained Aerial-refueling system direct fuel transfer by the craft equipment decreases in an exceedingly right smart degree the general dimensions of the pod. System provides the following:

1) Pod management all told the operational modes, as well as the emergency ones;

2) Transfer of the knowledge regarding the pod condition/operation to the craft, voice synthesizer and displaying of the knowledge on the Multifunctional Display;

3) Control at "ground works";

4) Recording of the pod operation knowledge on the wing and on ground employing a self contained recorder.

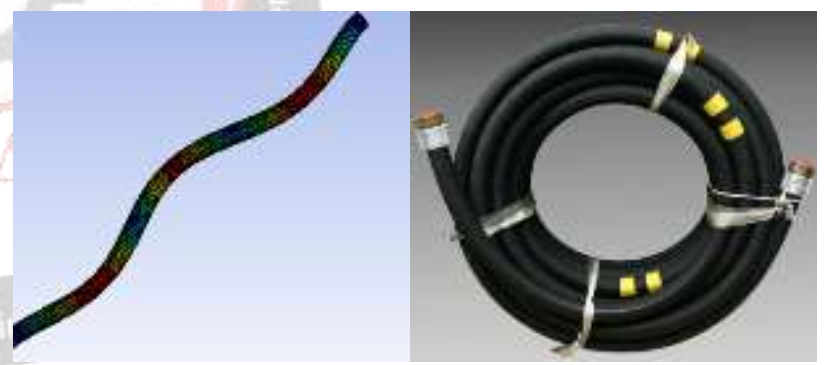

Fig.1 Refueling Hose. (From [8])

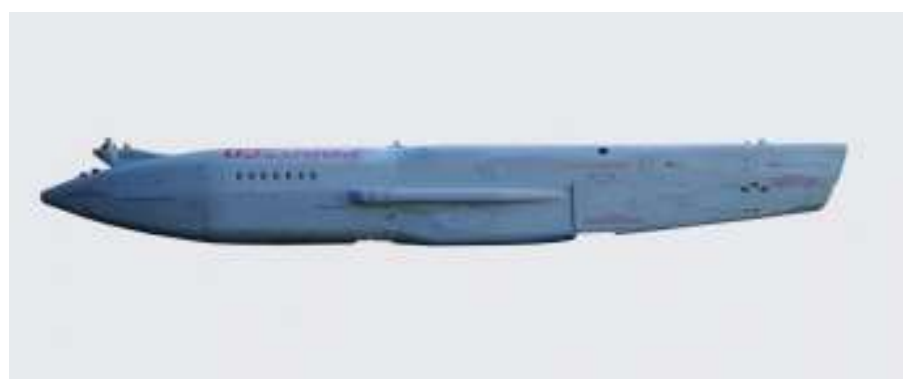

Fig.2 Refueling Pod. (From [9])

Aerial Refueling

Aerial fueling, additionally observed as air fueling, in-flight fueling (IFR), air to air fueling (AAR), and tanking, is that the method of transferring aviation fuel from one military craft (the tanker) to a different (the receiver) throughout flight. the two main fueling systems area unit probe and drogue, that is easier to adapt to existing craft, and also the 
flying boom, that offers quicker fuel transfer, however needs a boom operator stations.

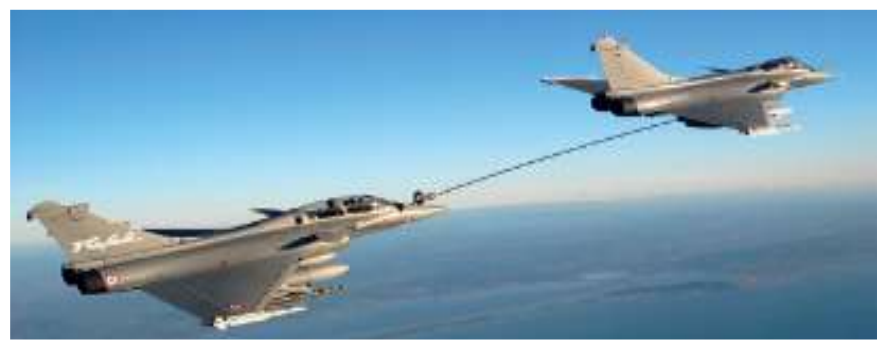

Fig.3 Aerial Refueling (from [2])

The procedure permits the receiving craft to stay mobile longer, extending it's vary or lallygag time on station. A series of air fueling will provide vary restricted solely by crew fatigue and engineering factors like engine oil consumption. as a results of the receiver craft could also be lidded up with extra fuel inside the air, air supply can modify a takeoff with a bigger payload which will be weapons, cargo, or personnel: the foremost takeoff weight is maintained by carrying less fuel and topping up once mobile or else, a shorter take-off roll may be achieved as a result of take-off may be at a lighter weight before fueling once mobile. Aerial fueling has additionally been thought-about as a method to cut back fuel consumption on long-distance flights larger than three to four thousand nautical miles $(5,600 \mathrm{~km} ; 3,500 \mathrm{mi})$. Potential fuel savings within the vary of $35-40 \%$ are calculable for long-haul flights (including the fuel used throughout the tanker missions). Usually, the craft providing the fuel is specially designed for the task, though provision pods may be fitted to existing craft styles if the "probe-and-drogue" system is to be used. the value of the provision instrumentation on each tanker and receiver craft and also the specialised craft handling of the craft to be refueled (very shut "line astern" formation flying) has resulted within the activity solely being employed in military operations. there's no notable regular civilian inflight provision activity. Originally utilized shortly before war II on a really restricted scale to increase the vary of British civilian transatlantic flying boats, so when war II on an oversized scale to increase the vary of strategic bombers, aerial provision since the Vietnam has been extensively employed in large-scale military operations. as an example, within the Gulf War and Iraq war, all coalition air sorties were air-refueled apart from many short-range onset sorties within the Kuwait space.

\section{WORKING}

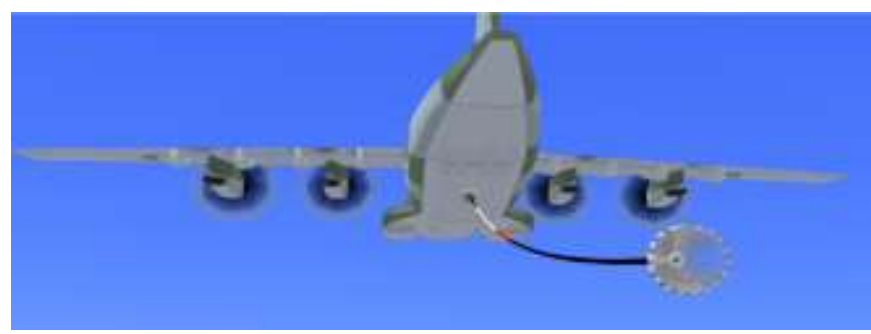

Fig.4 View of the Tanker (from [1])

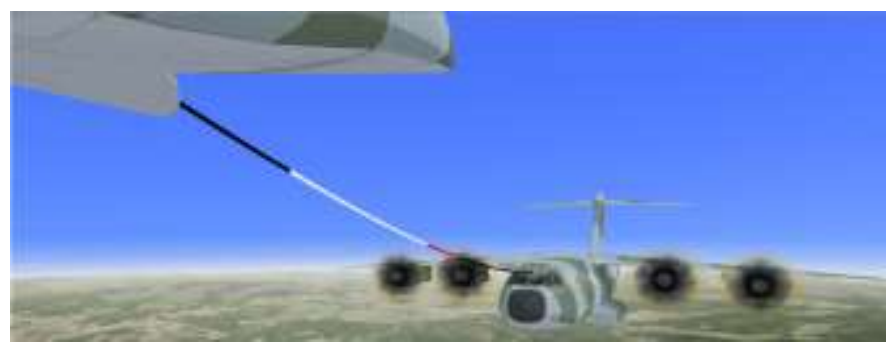

Fig.5 View of the Receiver (from [1])

\section{Probe and Drogue Modeling}

The selected state of affairs presently considers the centerline hose and drogue fuelling (fig. 6), however also can be tailored to refueling systems victimization PODs. The versatile hose is controlled by the questionable hose drum unit (HDU) that is found within the FMTA tanker craft directly behind the closed ramp door. Once absolutely deployed the hose encompasses a trailing length of eighteen to twenty four $\mathrm{m}$, whereas a diameter of $0.068 \mathrm{~m}$ and a particular "wet" weight of $4 \mathrm{~kg} / \mathrm{m}$ were assumed per ISO $1825: 2017$ standard. The high speed drogue is modeled with a tangle space of $0.186 \mathrm{~m}^{2}$ and a weight of $30 \mathrm{~kg}$.

Two approaches of modeling are used:

1. A physically deduced multi-body model and

2. A less complicated replacement model,

Which are enforced as a scheme within the overall model as well as tanker and receiver craft. The primary approach may be a lumped mass model with fifty coupled purpose lots. In given fig. the lots are set within the 1 to 50 joints are connected by rigid or semi-rigid (elasticity solely in longitudinal direction) and mass-less segments. Every of those purpose lots encompass a coefficient of drag related to it and reacts consequently to the native flow at its position. For reeling the hose out or in, solely the nearest phase to the HDU is changed between zero and most length, till ensuing joint seems or disappears at the fairing. The drogue is sculptural as rigid body, having a cone shaped pure mathematics and adequate aeromechanics making additionally aspect and elevate forces. This is often necessary so as to reply realistically to the bow wave. A contact model takes into consideration the cone-shaped inner and outer pure mathematics of the drogue making the correct reaction just in case of collision between the probe and therefore the inner or outer drogue surfaces. A higherorder modelling approach of the hose supported versatile components, this approach shall allow cutting back the quantity of components, compared to a model supported rigid or semi-rigid components. However, the equations area unit considerably additional sophisticated once victimization versatile components and thus this approach wasn't hand-picked for this work. 


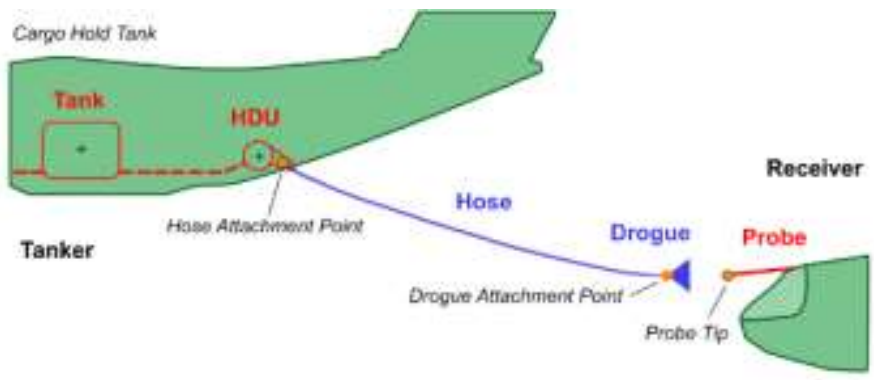

Fig.6 Sketch of the aerial refueling configuration.

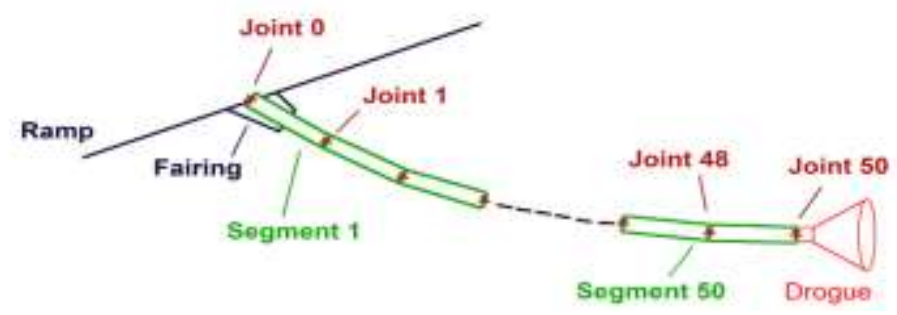

Fig .7 Geometric representation of hose model.

The multi body model of the hose and drogue permits learning dynamic effects of the hose and drogue system like hose whip, whereas the easy model approximates the behavior solely in an exceedingly \}ery simplified manner. Within the straightforward model, the drogue is sculptured as a degree mass reducing the mechanics forces to tug solely. The hose is sculptured as a mass-less line with a elastic characteristic. The form of the trailing hose is approximated by a conic providing conjointly the coordinates of the only joints for the next image as illustrated in figure. the probe and drogue contact is modelled with a one way magnet like attractor, that lets the drogue being catched by the probe tip once coming back shut enough. we can see The refueling system modules in figures. The block structure is equal for each the straightforward and therefore the multi-body hose/drogue models. The external interfaces of each models square measure identical specified they'll be changed simply within the simulation programs. The supply management signals square measure connected to the alleged tanker management station, a virtual tanker cockpit, providing (among others) the hose reel in/out command, predetermined fuel quantities, commanded fuel flows, yet as corresponding indicators for offloaded fuel, beacon fire standing, and plenty of others on Associate in Nursing emulated Aar panel. For readability reasons in figure eight, a block known as "Wind \& Environment" is placed aside of all alternative blocks (and with no affiliation to them) to symbolize that the wind field encompassing each craft yet as alternative physical properties - like gravity and region quantities square measure impacting/interacting with all components of the model.

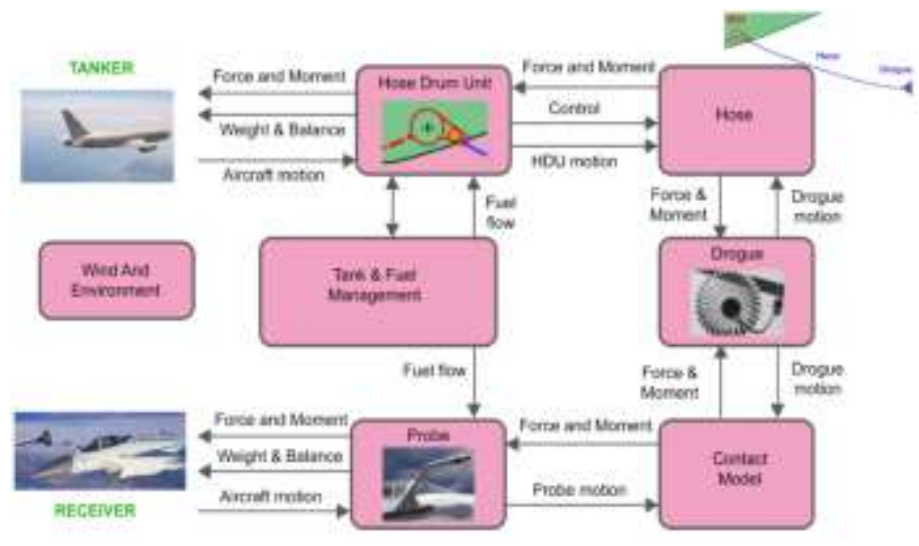

Fig. 8 probe \& drogue refueling model internal structure.

\section{Refueling Systems Modeling}

To ensure compatibility among the various tanker and receiver craft employed by North Atlantic Treaty Organization nations, the standard air-to-air refueling instrumentation and procedures square measure standardized and delineated in corresponding documents. For modelling the refueling system here, the refueling method is divided into ten phases numbered from zero to 9:

1) 0: drogue within pod or HDU

2) 1: drogue reeling out

3) 2: full path, clear contact

4) 3: contact, however not in fueling zone

5) 4: in fueling zone, fuel flow

6) 5: in standoff zone, fuel flow

7) 6: in cut-off zone

8) 7: fueling finished, disconnect

9) 8: separated

10) 9: drogue reeling in.

Phases 0,1 , and nine square measure active before and once the particular fueling method. The fueling method starts with part two once the receiver actively enters the questionable fueling box. This can be the safe and permissible space behind the tanker wherever probe-drogue contact and fueling shall occur. The transitions between the phases square measure controlled by the hose retraction standing, the contact standing, and therefore the (true) fuel flow to the receiver. The fuelling standing is indicated to the receiver pilot victimization red, amber and inexperienced signal lights close to the gap through that the hose is deployed. part two and three square measure indicated by a gradual amber beacon fire. To alter fuel flow, the receiver has got to push the drogue till the hose is backward by the HDU and reaches the fueling zone, that is indicated by markings on the hose. The hose retraction is accomplished by dominant the strain within the hose. Within the model this controller is found alongside the mechanism model within the HDU block. Among the fueling zone (phase 4) the fuel valve is opened and therefore the transfer of fuel is indicated by a gradual inexperienced light-weight. If the drogue is pushed in too way, the hose leaves the fueling 
zone and enters the stand-off zone (phase 5). During this part fuel remains transferred, however an extra flashing amber light-weight indicates the receiver pilot to fall back towards the fueling zone once more. on the far side the fueling and standoff zones the inexperienced light weight disappears, the amber light-weight remains flashing, and therefore the fuel flow is bring to a halt (phase three and part 6). Once the fueling for one receiver is finished (phase 7), a flashing inexperienced light-weight informs the receiver pilot to disconnect (phase 8) and leave the fueling box, permitting succeeding receiver - if applicable - to be refueled. that isn't terribly stunning since a really elaborate NATO standard7 has been used and unbroken up-to-date for a really while. The core of the "tank and refueling management" could be a state machine that's placed within the block known as "refueling phases and lights logic."

The 3 different blocks shown in figure ("preset/reset logic," "tank and provision logic," "tank weight and balance") square measure to blame for managing the fuel transfer from tanker to receiver and its implications.

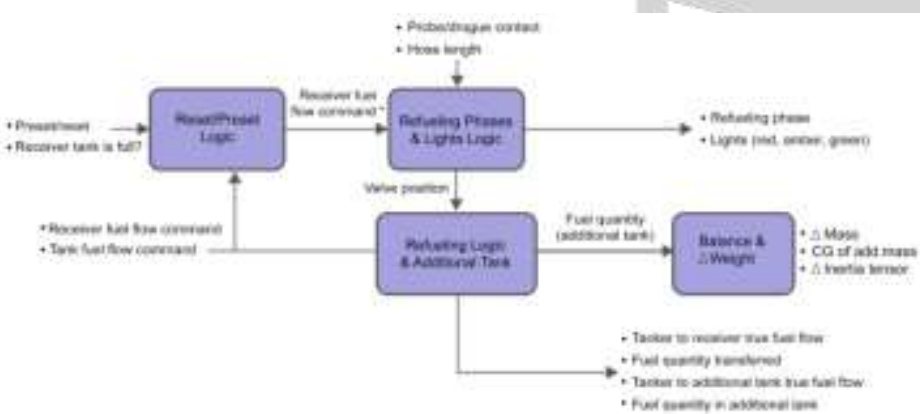

Fig.9 Internal structure of the "Tank and Refueling Management"

The first block permits employing a planned price for fuel amount that shall be transferred. Once this price is reached, the refueling system mechanically stops the fuel transfer and signals "disconnect" to the receiver. The planned price is about within the Aare panel of the tanker, wherever conjointly a reset may be commanded so as to refuel consequent receiver. The second block named "refueling phases and lights logic," as explained earlier, is to blame for stepping through the phases, setting the sunshine signals consequently and gap or closing the valve for fuel transfer. However, fuel will solely be transferred if enough fuel is obtainable within the tanker and therefore the receiver tank isn't full. These conditions square measure checked and handled within the "tank and provision logic" block. In real Aare eventualities, fuel may be transferred either from extra cargo deck tanks or directly from the own fuel compartments within the tanker. within the model, a cargo deck tank is usually gift and dealing as buffer between the tanker and receiver tanks (see figure). Consequently not solely the fuel flow to the receiver, however conjointly the fuel flow to the cargo deck tank needs to be thought of and controlled. betting on the reserve within the tank. The fuel flows to and from these tank is restricted and brings to an end, if one among the boundaries is reached. Mass, inertia and CG location of the extra additional square measure cargo tank are finally computed within the block "Tank Weight and Balance" and provided to the weight and balance scheme of the tanker model. the mass of fuel within the regular tanks is directly handled (in terms of weight and balance) by the premise FMTA models (tanker and receiver). However, the extra lots associated with the Hose Drum Unit, doable wing pods, extra tanks (and their content) and also the probe (as it may be unmounted) area unit computed within the Aare River scheme and transmitted to the FMTA models such they're properly taken into consideration within the equations of motion.

\section{REFUELING HOSE}

There are a unit numerous styles of hose that is employed in provision \{of numerous of varied of assorted \} styles of fuel in various fields. It ought to have fifteen to twenty meters length and fifty to fifty five millimeter diameter. Two or three layers area unit. Inner layer need to be fuel friendly and outer layer is for reinforcement. By considering ISO standards for provision hose (ex, 1825:2010, and 1825:2017) and taking MIL standards for hose. Additionally By taking reference with the hose that is employed in aviation/aircraft provision on ground as a result of fluid is same as on aerial provision and looking on the particular criteria like, the mechanical properties area unit higher than those of most different artificial rubbers.

1) Proof against gas and weathering.

2) The operation temperature vary of those compounds is from -30 to $+70^{\circ} \mathrm{C}$.

3) Working pressure is over fifteen bars.

4) Hardness needed more than fifty five IRHD.

5) It ought to be abrasion resistance.

6) It ought to be kinking resistance.

7) Suitable for low-temperature applications.

8) Requiring resistance to oils and fats, flame resistance or weather.

\section{Aerial Refueling hose which contacts with aviation fuel it contains below criteria,}

1) Resistant to ozone and weathering.

2) It is Suitable for low-temperature applications.

3) oil resistance

4) The operating temperature range is from -45 to $+120^{\circ} \mathrm{C}$.

5) Working pressure is up to $20 \mathrm{bar}$

6) Have excellent toughness.

7) Sunlight resistance.

8) Higher melting point (like $256{ }^{\circ} \mathrm{C}$ )

9) It can sustain higher temperatures

10) It has excellent tensile resistance

11) It has elongation resistance

12) It has good resilience 
13) It has tear resistance

14) It has good abrasion resistance

15) It has excellent low temperature flexibility.

\section{SAMPLE HOSE DRAWING}

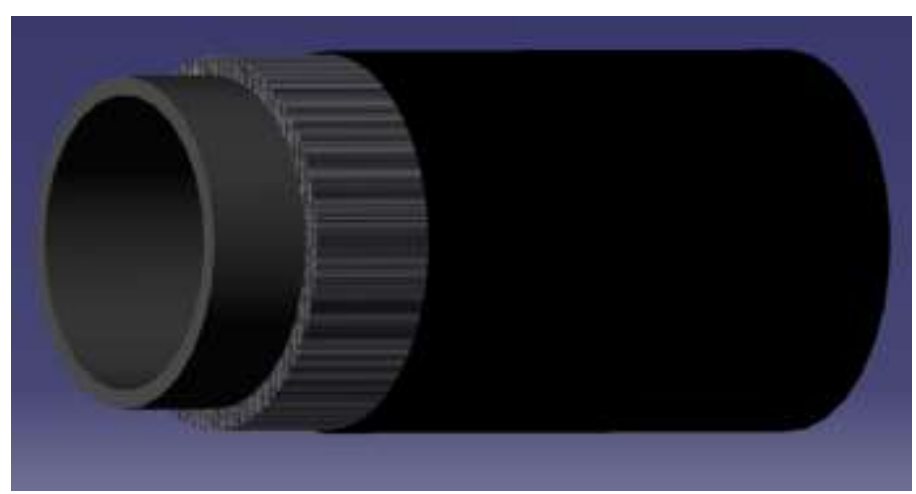

Fig.10 Sample model

\section{CONCLUSION}

This paper presented an overview of what is refueling hose, its working, where it is used, and its material properties. Refueling hose must have working or material criteria as we discuss in refueling hose section. It should be sustains all conditions and with reference of ISO standards as we mention we can find out relatable materials. Fig.10 shows clearly how refueling hose looks.

\section{REFERENCES}

[1] Nicolas Fezans and Thomas Jann "Modeling and Simulation for the Automation of Aerial Refueling of Military Transport Aircraft with the Probe \& Drogue System” Conference Paper · June 2017

[2] Jennifer L. Hansen, James E. Murray, and Norma V. Campos "The NASA Dryden AAR Project: A Flight Test Approach toan Aerial Refueling System" NASA Dryden Flight Research Center, Edwards, California, 93523.

[3] The Executive Director of the Joint Air Power Competence Centre (JAPCC) "Air-to-Air Refueling Flight Plan-An Assessment" Book February 2011

[4] Andrea Aversano Stabile and Giorgio Di Mizio "Enhancing Military Capabilities in Europe: The Case of Air-to-Air Refueling" Istituto Affari International journal ISSN 2532-6570 September 2018.

[5] Ujjar Bhandari_, Peter R. Thomas, Steve Bullockz and Thomas S Richardson "Bow Wave Effect in Probe and Drogue Aerial Refueling" Guidance, Navigation, and Control and Co-located Conferences August 19-22, 2013, Boston, MA

[6] Sandra R. Scagliusi, Sumair G. Araújo, Liliane Landini and Ademar B. Lugão "study of properties of chloroprene rubber Devulcanizate by radiation in microwave" 2009 International Nuclear Atlantic Conference.

[7] Richard.M.Tanner M.B.E "History of air to air refueling" A book 2006.

[8] www.directindustry.com/prod/elaflex/product-19322-997171.html

[9] https://happyrubberhose.en.made-inchina.com/product/sBSnoDOvLJrk/China-Aircraft Refueling-HoseComparable-to-Paker.html. 